\title{
An Aggregate Production Plan for a Biscuit Manufacturing Plant Using Integer Linear Programming
}

\author{
Dilishiya Kalpani De Silva, Wasantha Bandara Daundasekara \\ Department of Mathematics, Faculty of Science, University of Peradeniya, Peradeniya, Sri Lanka \\ Email: dilishiya.kalpani@gmail.com
}

How to cite this paper: De Silva, D.K. and Daundasekara, W.B. (2019) An Aggregate Production Plan for a Biscuit Manufacturing Plant Using Integer Linear Programming. Open Access Library Journal, 6: e5743. https://doi.org/10.4236/oalib.1105743

Received: August 30, 2019

Accepted: November 25, 2019

Published: November 28, 2019

Copyright $\odot 2019$ by author(s) and Open Access Library Inc.

This work is licensed under the Creative Commons Attribution International License (CC BY 4.0).

http://creativecommons.org/licenses/by/4.0/ (c) (i) Open Access

\begin{abstract}
Effective planning, scheduling, and synchronization of all production activities are the key responsibilities of the management of a manufacturing plant. Therefore, it is necessary for the management of the plant to design the production process so that the total production cost is minimized, subject to the available resources that cannot be compromised. In this study, a biscuit manufacturing plant is selected and an integer linear programming (ILP) model is formulated to determine aggregate number of batches that the plant should produce from each product per month so that monthly demand is satisfied with available resources. The objective is to minimize the monthly production cost of the plant. The required data were collected from the production plant for a period of one month, and then, the objective function and constraints were formulated. The management has given a paramount importance in satisfying the demand so that there will not be any unsatisfied customer. According to the managerial requirement, any feasible solution obtained by the model must satisfy the demand. Therefore, demand constraint is considered as a hard constraint. The management is forced to adjust the labour and machine requirements more frequently according to the monthly demand. Thus, labour and machine hour constraints are considered as soft constraints. Formulated ILP model was implemented as a spreadsheet model in Excel and solved using Excel Solver which uses the simplex algorithm and incorporates the integer requirement of the model when finding the optimal solution. Total available labour and machine hours can be changed within a particular range until a feasible solution is found. The solved model determines the number of batches to be produced from each product and the corresponding minimum cost per month. By implementing this production plan, manufacturing excess of biscuits can be avoided and hence utilizes the physical and human resources to the optimum manner. Additionally, the machine and la-
\end{abstract}


bour idle times and the needed overtime hours can be identified using the solution while the additional overtime cost will be added to the monthly production cost.

\section{Subject Areas}

Corporate Governance

\section{Keywords}

Integer Linear Programming, Soft Constraints, Hard Constraints, Spreadsheet Model, Excel Solver, Simplex Algorithm

\section{Introduction}

Proper functioning of a manufacturing plant requires efficient planning, scheduling, and synchronization of all production activities. Thus, a production plan (PP) is an important part of a business plan that the manufacturing or production department is responsible for developing. It is necessary for the management of the plant to determine the total amount of output that the manufacturing plant should produce from each period in the planning horizon in order to satisfy the customer demand with the limited available resources in the plant. The output is generally expressed in terms of units of measurement such as tons, liters, kilograms and batches. A quantitative solution for the PP problem can be found in different ways. One method is to use a mathematical model to solve a PP problem. The applications of Operations Research (OR) are widely used in industrial sector due to its ability to optimize a given scenario resulting in maximum possible gain. In practical situations, linear programming is a part of a very essential area of mathematics termed "optimization techniques". A mathematical model can be formulated using linear programming (LP) [1] with the objective of minimizing the cost or maximizing the profit without violating the constraints of limited resources and satisfying the demand constraint in order to determine the number of units to be produced from each item. Tingley [2] revealed that $\mathrm{LP}$ is a conventionally used technique. However, in order to apply LP to a production planning problem, the data input should be uniquely determined.

In this study, a quantitative approach is used by means of operations research to solve an aggregate production planning (APP) problem for a biscuit manufacturing plant. By implementing this production plan, manufacturing excess of biscuits can be avoided and hence utilizes the physical and human resources to the optimum manner. This can be achieved by building up a mathematical model using LP. LP is the procedure of taking different linear inequalities considering some situations and finding the best feasible solution subject to those requirements. Using LP techniques to solve PP problems accounts for vast amount of studies found in the literature [3]-[10]. In these studies, where LP techniques 
were used, many authors attempted to solve the APP problem. In APP, the aim is to obtain overall (aggregate) production quantities for each product. Other approaches such as goal programming have been used to solve the APP problem in the literature [11] [12] [13]. Since defining goals is a managerial decision, the problem is reduced to a linear programming problem. In real-world APP problems, the input data or parameters, such as demand, resources, cost and objective function are often uncertain (fuzzy) because some information is incomplete or unavailable. Therefore, Fuzziness is included in most models in previous studies to find a solution to APP [7] [8] [14]. Moreover, Wang and Fang [15] incorporated the fuzzy nature of parameters and presented a fuzzy linear programming method for solving the APP. However, the data such as cost and resources for this study were obtained from the manufacturing plant. The complexity of the problem reduces as the monthly demand is decided by the top management and informed the production managers at the beginning of each month. Thus, as mentioned earlier, an LP model can be developed to solve this PP problem considering only one month as the data input is uniquely determined. The aim of this study is to determine the number of batches to be produced from each product per month in order to satisfy the monthly demand with the available resources while minimizing the production cost. Owing to the fact that the plant does not produce partial batches, all the variables are restricted to be integers. Thus, in this study, an integer linear programming (ILP) model [16] is used to solve the PP problem. In our mathematical model all the decision variables are restricted to be integers. However, when only a set of variables are integers, the problem can be solved using mixed integer linear programming (MILP) problem [17] [18].

If the plant has the capability of producing biscuits according to the monthly demand, based on their past experience, without using further quantitative analytical methods, then most of the biscuits will remain in the finished-goods stores for a longer period, before they are sent to the warehouses or other distributing areas. As a result, more often, by the time customer consumes the product, biscuits are reaching their expiration date, so that the moisture level of biscuits will be increased, the appearance and the colour may have changed, and the crispiness will be reduced. Once such low-quality products are released to the market, the goodwill of the customer regarding the product would be lost. An improved PP for the production plant is extremely important since a better production plan will reduce the time that the finished goods remain in the stores, thus, prevent the additional inventory costs and the quality of the product will be fresh by the time consumer consumes it. In addition, the product can be sent to the market according to the demand without unnecessary delays.

In the production process, the wet dough starts to process at the mixing and passes through different types of machineries in forming section such as lamination, gauge rolls, relaxing web, and moulding, and subsequently through oven, cooling web and stacking web. This is a continuous process and the plant has only one production line and therefore, parallel production is not possible (see 
Figure 1 for the production process). The plant is producing various types of products, which are mainly categorized as soft dough and hard dough biscuits. In addition, there are certain products, which are unique and need further manufacturing process such as oiling, creaming and flavouring. These deviations are taken into account when the mathematical model is formulated. The range of products that are produced in the plant is presented in Table 1 . The table categorises the products as soft dough and hard dough and specifies the biscuits which use the additional processing; creaming and flavouring. Furthermore, the coefficients for both objective function and constraints are calculated to develop the mathematical model by considering the process of the biscuit plant.

\section{Materials and Methods}

A mathematical model to determine the number of batches to be produced from each item (see Table 1 for all the available products in this plant) was formulated using ILP with the objective of minimizing the cost without violating the

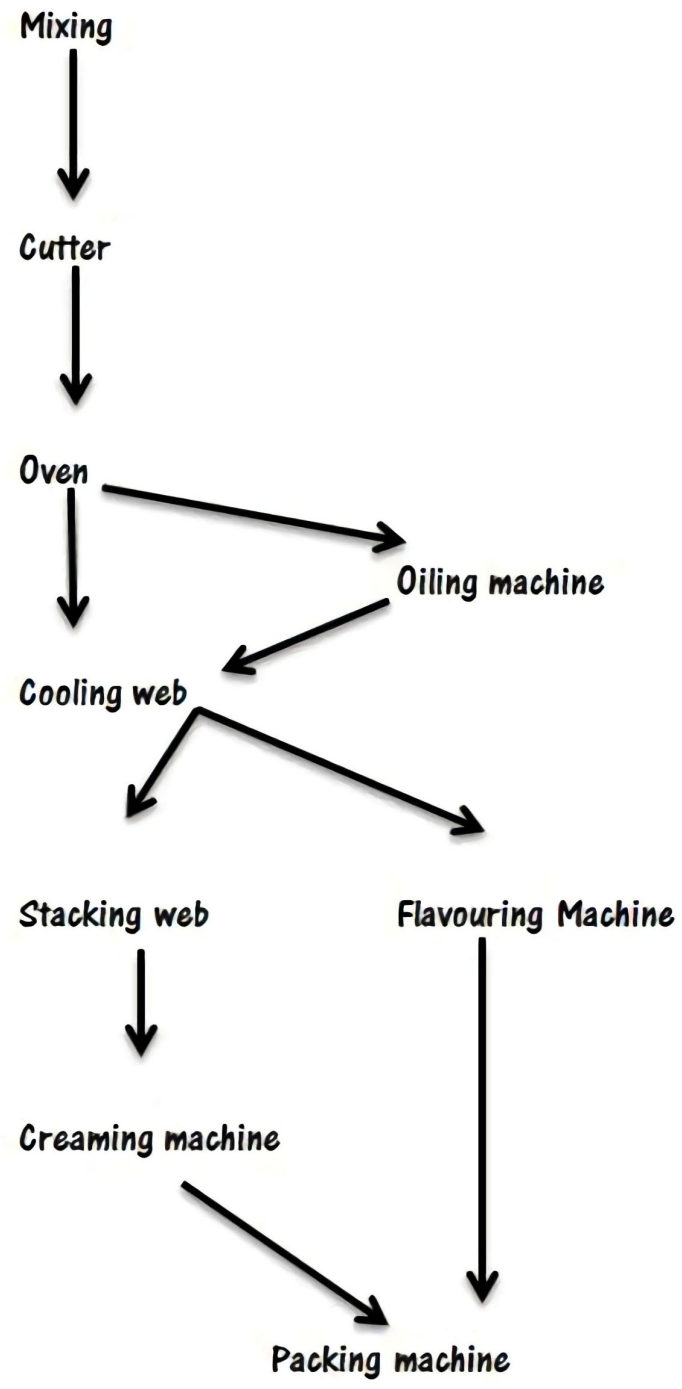

Figure 1. Production process. 
Table 1. Range of products.

\begin{tabular}{|c|c|c|c|}
\hline Type & Product & Creaming & Flavouring \\
\hline \multirow{6}{*}{ Hard dough } & Cheese and Onions $\left(\mathrm{P}_{8}\right)$ & & Yes \\
\hline & Cheese Cuts $\left(\mathrm{P}_{7}\right)$ & & Yes \\
\hline & Cream Cracker $\left(\mathrm{P}_{1}\right)$ & & \\
\hline & Hot Chilly Byte $\left(\mathrm{P}_{9}\right)$ & & Yes \\
\hline & Lemon Puff $\left(\mathrm{P}_{10}\right)$ & Yes & \\
\hline & Marie $\left(\mathrm{P}_{5}\right)$ & & \\
\hline \multirow{5}{*}{ Soft dough } & Onion Byte $\left(\mathrm{P}_{6}\right)$ & & Yes \\
\hline & Chocolate Cream $\left(\mathrm{P}_{11}\right)$ & Yes & \\
\hline & Nice $\left(P_{2}\right)$ & & \\
\hline & Sorties $\left(\mathrm{P}_{3}\right)$ & & \\
\hline & Teasty $\left(\mathrm{P}_{4}\right)$ & & \\
\hline
\end{tabular}

constraints of limited resources and satisfying the demand constraint. All the necessary data were collected and the coefficients corresponding to the objective and constraints were estimated as demonstrated in the following sections.

\subsection{Formulating the Mathematical Model}

Let $x_{i}$ be the number of batches to be produced from the $i^{\text {th }}$ product $\left(P_{i}\right)$ per month, where $i=1,2, \cdots, 11$.

\subsubsection{Objective}

The objective is to minimize the monthly manufacturing cost of unpacked biscuits (baked biscuits, which are not packed but stacked into the bins). The production cost per kilogram of biscuits for unpacked biscuit was collected as raw data. It involves raw material cost, labour cost, fuel cost for the oven, electricity etc. After incorporating these costs, the objective function was formulated as follows:

Let $C_{i}$ be the production cost per finished batch of the $i^{\text {th }}$ product.

$$
\min Z=\sum_{i=1}^{11} C_{i} x_{i}+O C ;
$$

where $C_{i}$ is the cost per batch of the $I^{\text {th }}$ product and $O C$ is the overtime cost.

The wastage produced in the process of biscuit manufacturing and weight losses at each section are illustrated in Table 2. Afterward, all the wastages and weight losses mentioned in Table 2 were reduced from the weight of the wet dough mixture. The model is developed and solved assuming that these are the only wastages that will occur in the production process. All the necessary data are exhibited in Table 3. It enumerates the weight of a baked biscuit batch $\left(B_{i}\right)$. Given that the cost per kilogram $\left(k_{i}\right)$ was collected as raw data, the cost per batch of the $i^{\text {th }}$ product $\left(C_{i}\right)$ can be calculated using the following formulas. The computations are done in Table 4. 
Table 2. The wastage produced in the process of biscuit manufacturing and weight losses at each section.

\begin{tabular}{cccccc}
\hline Product $\left(\mathrm{P}_{\mathrm{i}}\right)$ & $\begin{array}{c}\text { Dough Weight } \\
(\mathrm{Kg})\end{array}$ & $\begin{array}{c}\text { Baking } \\
\text { loss } \%\end{array}$ & $\begin{array}{c}\text { Waste at mixing Waste at cutter } \\
(\mathrm{kg})\end{array}$ & $\begin{array}{c}\text { Waste in cooling \& } \\
(\mathrm{kg})\end{array}$ & $\begin{array}{c}\text { stacking \% (from } \\
\text { oven output) }\end{array}$ \\
\hline $\mathrm{P}_{1}$ & 550 & 26 & 1 & 1.5 & 0.5 \\
$\mathrm{P}_{2}$ & 650 & 13 & 0.75 & 2 & 0.5 \\
$\mathrm{P}_{3}$ & 615 & 13 & 0.75 & 2 & 0.5 \\
$\mathrm{P}_{4}$ & 580 & 13 & 0.75 & 2 & 0.5 \\
$\mathrm{P}_{5}$ & 619 & 23 & 1 & 1.5 & 0.5 \\
$\mathrm{P}_{6}$ & 525 & 27 & 1 & 1.5 & 0.5 \\
$\mathrm{P}_{7}$ & 600 & 27 & 1 & 1.5 & 0.5 \\
$\mathrm{P}_{8}$ & 600 & 27 & 1 & 1.5 & 0.5 \\
$\mathrm{P}_{9}$ & 580 & 27 & 1 & 1.5 & 0.5 \\
$\mathrm{P}_{10}$ & 540 & 22 & 1 & 1.5 & 0.5 \\
$\mathrm{P}_{11}$ & 630 & 12 & 0.75 & 2 & 0.5 \\
\hline
\end{tabular}

Table 3. Weights of baked biscuit batches.

\begin{tabular}{cccccccc}
\hline $\begin{array}{c}\text { Product } \\
\left(\mathrm{P}_{\mathrm{i}}\right)\end{array}$ & $\begin{array}{c}\text { Dough } \\
\text { weight } \\
(\mathrm{Kg})\end{array}$ & $\begin{array}{c}\text { Waste in } \\
\text { Mixing } \\
(\mathrm{Kg})\end{array}$ & $\begin{array}{c}\text { Oven } \\
\text { input }(\mathrm{Kg})\end{array}$ & $\begin{array}{c}\text { Baking } \\
\text { loss }(\mathrm{kg})\end{array}$ & $\begin{array}{c}\text { Oven } \\
\text { output } \\
(\mathrm{kg})\end{array}$ & $\begin{array}{c}\text { Waste in cooling \& } \\
\text { stacking }(\mathrm{kg}) \\
\text { (from oven out- } \\
\text { put })\end{array}$ & $\begin{array}{c}\text { Final weight of } \\
\text { the baked biscuit } \\
\text { batch }(\mathrm{Kg})-B_{i}\end{array}$ \\
\hline $\mathrm{P}_{1}$ & 550 & 2.5 & 547.5 & 142.35 & 405.15 & 2.03 & 403.12 \\
$\mathrm{P}_{2}$ & 650 & 2.75 & 647.25 & 84.14 & 563.11 & 2.82 & 560.29 \\
$\mathrm{P}_{3}$ & 615 & 2.75 & 612.25 & 79.59 & 532.66 & 2.66 & 529.99 \\
$\mathrm{P}_{4}$ & 580 & 2.75 & 577.25 & 75.04 & 502.21 & 2.51 & 499.7 \\
$\mathrm{P}_{5}$ & 619 & 2.5 & 616.5 & 141.8 & 474.71 & 2.37 & 472.33 \\
$\mathrm{P}_{6}$ & 525 & 2.5 & 522.5 & 141.08 & 381.43 & 1.91 & 379.52 \\
$\mathrm{P}_{7}$ & 600 & 2.5 & 597.5 & 161.33 & 436.18 & 2.18 & 433.99 \\
$\mathrm{P}_{8}$ & 600 & 2.5 & 597.5 & 161.33 & 436.18 & 2.18 & 433.99 \\
$\mathrm{P}_{9}$ & 580 & 2.5 & 577.5 & 155.93 & 421.58 & 2.11 & 419.47 \\
$\mathrm{P}_{10}$ & 540 & 2.5 & 537.5 & 118.25 & 419.25 & 2.1 & 417.15 \\
$\mathrm{P}_{11}$ & 630 & 2.75 & 627.25 & 75.27 & 551.98 & 2.76 & 549.22 \\
\hline
\end{tabular}

Table 4. Cost per batch for each product.

\begin{tabular}{cccc}
\hline Product $\left(\mathrm{P}_{\mathrm{i}}\right)$ & $\begin{array}{c}\text { Production cost } \\
\text { per kilogram (Rs) }-K_{i}\end{array}$ & $\begin{array}{c}\text { Final weight of the } \\
\text { baked biscuit batch }(\mathrm{Kg})-B_{i}\end{array}$ & Cost per batch (Rs) $-C_{i}$ \\
\hline $\mathrm{P}_{1}$ & 150.0015876 & 403.12 & $60,468.64$ \\
$\mathrm{P}_{2}$ & 133.000464 & 560.29 & $74,518.83$ \\
$\mathrm{P}_{3}$ & 117.0009245 & 529.99 & $62,009.32$ \\
$\mathrm{P}_{4}$ & 115.9991795 & 499.7 & $57,964.79$ \\
\hline
\end{tabular}




\section{Continued}

\begin{tabular}{llll}
\hline $\mathrm{P}_{5}$ & 124.0003811 & 472.33 & $58,569.1$ \\
$\mathrm{P}_{6}$ & 149.9991568 & 379.52 & $56,927.68$ \\
$\mathrm{P}_{7}$ & 260.0024655 & 433.99 & $112,838.47$ \\
$\mathrm{P}_{8}$ & 220.0020968 & 433.99 & $95,478.71$ \\
$\mathrm{P}_{9}$ & 129.9991179 & 419.47 & $54,530.73$ \\
$\mathrm{P}_{10}$ & 170.0015342 & 417.15 & $70,916.14$ \\
$\mathrm{P}_{11}$ & 180.0000364 & 549.22 & $98,859.62$ \\
\hline
\end{tabular}

Table 5. Total demand for each product.

\begin{tabular}{|c|c|c|c|c|c|}
\hline Product $\left(\mathrm{P}_{\mathrm{i}}\right)$ & SKU (g) & $\begin{array}{c}\text { No of packets } \\
\text { in a box }\end{array}$ & $\begin{array}{l}\text { Demand } \\
\text { (in boxes) }\end{array}$ & $\begin{array}{l}\text { Total demand for } \\
\text { different SKUs }(\mathrm{kg})\end{array}$ & $\begin{array}{l}\text { Total demand for each } \\
\text { product type (Kg) }\end{array}$ \\
\hline \multirow{3}{*}{$\mathrm{P}_{1}$} & 125 & 50 & 1475 & 9218.75 & \multirow{3}{*}{19,769} \\
\hline & 190 & 24 & 1875 & 8550 & \\
\hline & 500 & 4 & 1000 & 2000 & \\
\hline \multirow[b]{2}{*}{$\mathrm{P}_{2}$} & 100 & 50 & 2500 & 12,500 & \multirow[b]{2}{*}{15,500} \\
\hline & 500 & 4 & 1500 & 3000 & \\
\hline \multirow{2}{*}{$\mathrm{P}_{3}$} & 75 & 50 & 47,500 & 178,125 & \multirow{2}{*}{19,200} \\
\hline & 320 & 4 & 15,000 & 19,200 & \\
\hline \multirow[b]{2}{*}{$\mathrm{P}_{4}$} & 60 & 50 & 45,000 & 135,000 & \multirow[b]{2}{*}{21,000} \\
\hline & 300 & 4 & 17,500 & 21,000 & \\
\hline \multirow{2}{*}{$\mathrm{P}_{5}$} & 80 & 50 & 4250 & 17,000 & \multirow{2}{*}{18,050} \\
\hline & 300 & 4 & 875 & 1050 & \\
\hline \multirow[b]{2}{*}{$\mathrm{P}_{6}$} & 30 & 20 & 8750 & 5250 & \multirow{2}{*}{10,320} \\
\hline & 130 & 20 & 1950 & 5070 & \\
\hline \multirow{2}{*}{$\mathrm{P}_{7}$} & 170 & 24 & 2250 & 9180 & \multirow{2}{*}{12,015} \\
\hline & 210 & 10 & 1350 & 2835 & \\
\hline $\mathrm{P}_{8}$ & 25 & 20 & 22,500 & 11,250 & 11,250 \\
\hline $\mathrm{P}_{9}$ & 30 & 20 & 20,000 & 12,000 & 12,000 \\
\hline \multirow[b]{2}{*}{$\mathrm{P}_{10}$} & 100 & 48 & 2150 & 10,320 & \multirow[b]{2}{*}{17,520} \\
\hline & 200 & 24 & 1500 & 7200 & \\
\hline \multirow[b]{2}{*}{$\mathrm{P}_{11}$} & 100 & 50 & 2625 & 13,125 & \multirow{2}{*}{14,725} \\
\hline & 400 & 4 & 1000 & 1600 & \\
\hline
\end{tabular}

$B_{i}=$ Dough Weight - Waste in Mixing - Baking Loss

- Waste in Cooling \& Stacking

$C_{i}=$ Production cost per kilogram of biscuits $\left(K_{i}\right)$

$\times$ Weight of a baked biscuit batch $\left(B_{i}\right)$

Hence, the objective function for the concerned problem can be written as: 


$$
\begin{aligned}
\min Z= & 60468.64 x_{1}+74518.83 x_{2}+62009.32 x_{3}+57964.79 x_{4} \\
& +58569.10 x_{5}+56927.68 x_{6}+112838.47 x_{7}+95478.71 x_{8} . \\
& +54530.73 x_{9}+70916.14 x_{10}+98859.62 x_{11}
\end{aligned}
$$

\subsubsection{Constraints}

Satisfying all constraints is essential for the feasibility. However, many models contain two categories of constraints: hard constraints that must be satisfied by any feasible solution and the soft constraints of different relative importance may or may not be satisfied. Hvolby and Steger-Jensen [19] discussed using soft constraints and hard constraints in production planning. The hard constraints stipulate the set of feasible solutions, and the soft constraints stipulate a function to be optimized in deciding between the feasible solutions. If both kinds of constraints exist in a model, soft constraints can be adjusted, until a feasible solution is found.

\section{1) Hard Constraint}

\section{- Demand constraint}

The management has given utmost importance in satisfying the demand so that there will not be any unsatisfied customer. Any feasible solution obtained by the model must satisfy the demand. Therefore, for this study, demand constraint was considered as a hard constraint.

Since $X_{i}$ is the number of batches to be produced from the $i^{\text {th }}$ product, $B_{i} X_{i}$ gives the total number of kilograms that have to be produced from the $i^{\text {th }}$ product per month. This amount should be equal to the demand of each product (in kilograms) to satisfy the demand as the plant does not want to produce any excess amount of biscuits. Thus, the demand constraint, in general, can be written as follows:

$$
B_{i} x_{i} \geq D_{i} \text { for } i=1,2, \cdots, 11 ;
$$

where $D_{i}$ is the monthly demand in kilograms for the $i^{\text {th }}$ product.

The monthly demand is decided by the top management which is passed away to the biscuit plant at the beginning of every month. The demand is expressed as the number of boxes of biscuits needed for different stock keeping units (SKU) from each product. These data were collected from the manufacturing plant and monthly demand in kilograms for each product was calculated utilizing these data. Table 5 enumerates all the necessary calculations to find the total demand in kilograms per month from each product.

As illustrated in Table 1, the product types, Lemon Puff $\left(\mathrm{P}_{10}\right)$ and Chocolate cream $\left(P_{11}\right)$ have a cream layer. Thus, in Table 6 , the cream weight was reduced

Table 6. Biscuit weight without cream.

\begin{tabular}{ccccc}
\hline Product $\left(\mathrm{P}_{\mathrm{i}}\right)$ & $\begin{array}{c}\text { Cream } \\
\text { percentage \% }\end{array}$ & Total Weight $(\mathrm{kg})$ & Cream weight $(\mathrm{kg})$ & $\begin{array}{c}\text { Weight without } \\
\text { cream }(\mathrm{kg})\end{array}$ \\
\hline $\mathrm{P}_{10}$ & 30 & 17,520 & 5256 & 12,264 \\
$\mathrm{P}_{11}$ & 25 & 14,725 & 3681.25 & $11,043.75$ \\
\hline
\end{tabular}


from the total demand which was calculated in Table 5 for $\mathrm{P}_{10}$ and $\mathrm{P}_{11}$ in order to calculate the total amount of baked biscuits that should be produced.

After calculating all the coefficient values and right-hand side values which are the requirements, the demand constraints for each product can be written as follows:

$$
\begin{gathered}
403.12425 x_{1} \geq 19769 \\
560.2919625 x_{2} \geq 15500 \\
529.9942125 x_{3} \geq 19200 \\
499.6964625 x_{4} \geq 21000 \\
472.331475 x_{5} \geq 18050 \\
379.517875 x_{6} \geq 10320 \\
433.994125 x_{7} \geq 12015 \\
433.994125 x_{8} \geq 11250 \\
419.467125 x_{9} \geq 12000 \\
417.15375 x_{10} \geq 12264 \\
549.2201 x_{11} \geq 11043.75 .
\end{gathered}
$$

\section{2) Soft Constraints}

The manufacturing company has limited amount of resources. Therefore, it is essential to consider available resources in the plant when minimizing the manufacturing cost. When the biscuits are manufactured, manufacturing process cannot exceed consuming the available amount of resources such as the number of labourers and the machine capacity. The management is repeatedly adjusting the labour and machine requirements according to the monthly demand. Thus, in this study, labour and machine hour constraints were considered as soft constraints.

\section{- Machine Hours}

A batch of each product takes a certain processing time. The required total processing time for the monthly production should be less than or equal to total available machine hours per month. If the demand cannot be satisfied with the available total machine hours, number of working hours per day and working days per month can be increased up to some level in the model solving step. Therefore, machine hour constraint was considered as a soft constraint. Then, the machine hour constraint, in general, is as follows:

$$
\sum_{i=1}^{11} t_{i} x_{i} \leq T \text { for } i=1,2, \cdots, 11,
$$

where $t_{i}$ is the total processing time (in minutes) per batch of the $i^{\text {th }}$ product and $T$ is the available machine time (in minutes) per month.

Available machine hours per month are calculated in Table 7 while processing time for a batch of each product is illustrated in Table 9. The machine hour constraint can be written as follows: 
Table 7. Available machine hours per month.

\begin{tabular}{cccc}
\hline $\begin{array}{c}\text { Number of working hours Number of working days per } \\
\text { per day }\end{array}$ & $\begin{array}{c}\text { Total available machine } \\
\text { hours (T) }\end{array}$ & T (min) \\
\hline 8 & 25 & 200 & 12000 \\
\hline & & \\
& $30 x_{1}+25 x_{2}+20 x_{3}+26 x_{4}+40 x_{5}+50 x_{6}+45 x_{7}$ \\
& $+50 x_{8}+50 x_{9}+30 x_{10}+30 x_{11} \leq 12000$
\end{tabular}

\section{- Labor hour constraint}

The required labour hours for the monthly production should be less than the available labour hours per month. Thus, the labour hour constraint for each section; mixing, cutter, baking and cooling, and stacking can be formulated, in general, as follows:

$$
\sum_{i=1}^{11} t_{i} l_{I} x_{i} \leq L
$$

for each of the four sections mixing, cutter, baking and cooling, and stacking, where $l_{i}$ is the number of labourers needed for each production section, $t_{i}$ is the processing time (in minutes) per batch of the $I^{\text {th }}$ product through each section and $L$ is the total available labour hours.

A fixed number of labourers are allocated to each section of the production plant (see Table 8). Among these labourers, different numbers of labourers are assigned into each section during the production of different products (see Table 9). Moreover, the calculations of the required labour time for each section during the production are demonstrated in Table 9 and the available labour time in minutes is shown in Table 8.

Since the number of working days or hours can be adjusted until a feasible solution is found, this constraint is also identified as a soft constraint. Therefore, labour constraint for each section for this PP problem can be presented as follows:

Mixing:

$$
\begin{aligned}
& 300 x_{1}+300 x_{2}+240 x_{3}+312 x_{4}+400 x_{5}+500 x_{6}+450 x_{7} \\
& +500 x_{8}+500 x_{9}+300 x_{10}+360 x_{11} \leq 144000
\end{aligned} .
$$

Cutter:

$$
\begin{aligned}
& 180 x_{1}+125 x_{2}+100 x_{3}+130 x_{4}+240 x_{5}+300 x_{6}+270 x_{7} \\
& +300 x_{8}+300 x_{9}+180 x_{10}+150 x_{11} \leq 72000
\end{aligned}
$$

Baking and Cooling:

$$
\begin{aligned}
& 150 x_{1}+125 x_{2}+100 x_{3}+130 x_{4}+200 x_{5}+250 x_{6}+225 x_{7} \\
& +250 x_{8}+250 x_{9}+150 x_{10}+150 x_{11} \leq 72000
\end{aligned} .
$$

Stacking:

$$
\begin{aligned}
& 420 x_{1}+450 x_{2}+360 x_{3}+468 x_{4}+800 x_{5}+300 x_{6}+270 x_{7} \\
& +300 x_{8}+300 x_{9}+180 x_{10}+540 x_{11} \leq 240000
\end{aligned} .
$$

In addition, all the $x_{i}$ values should be positive integers as the plant does not produce partial batches. That is, $x_{i} \geq 0$ and integer for $i=1,2, \cdots, 11$. 
Table 8. Number of labours assigned for each section and available labour hours per month.

\begin{tabular}{cccccc}
\hline Section & $\begin{array}{c}\text { Available number } \\
\text { of labours }\end{array}$ & $\begin{array}{c}\text { Number of } \\
\text { days }\end{array}$ & $\begin{array}{c}\text { Number of } \\
\text { hours }\end{array}$ & L (h) & L (min) \\
\hline Mixing & 12 & 25 & 8 & 2400 & 144,000 \\
Cutter & 6 & 25 & 8 & 1200 & 72,000 \\
Baking and Cooling & 5 & 25 & 8 & 1200 & 72,000 \\
Stacking & 20 & 25 & 8 & 4000 & 240,000 \\
\hline
\end{tabular}

Table 9. Required labour time.

\begin{tabular}{|c|c|c|c|c|c|c|c|c|c|}
\hline \multirow{2}{*}{$\begin{array}{c}\text { Product } \\
\left(\mathrm{P}_{\mathrm{i}}\right)\end{array}$} & \multirow{2}{*}{$\begin{array}{l}\text { Processing } \\
\text { time per } \\
\text { batch } \\
(\min )-t_{i}\end{array}$} & \multicolumn{4}{|c|}{ Number of labourers needed } & \multicolumn{4}{|c|}{ Required labour time (min) } \\
\hline & & Mixing & Cutter & $\begin{array}{c}\text { Baking \& } \\
\text { Cooling }\end{array}$ & Stacking & Mixing & Cutter & $\begin{array}{c}\text { Baking \& } \\
\text { Cooling }\end{array}$ & Stacking \\
\hline $\mathrm{P}_{1}$ & 30 & 10 & 6 & 5 & 14 & 300 & 180 & 150 & 420 \\
\hline $\mathrm{P}_{2}$ & 25 & 12 & 5 & 5 & 18 & 300 & 125 & 125 & 450 \\
\hline $\mathrm{P}_{3}$ & 20 & 12 & 5 & 5 & 18 & 240 & 100 & 100 & 360 \\
\hline $\mathrm{P}_{4}$ & 26 & 12 & 5 & 5 & 18 & 312 & 130 & 130 & 468 \\
\hline $\mathrm{P}_{5}$ & 40 & 10 & 6 & 5 & 20 & 400 & 240 & 200 & 800 \\
\hline $\mathrm{P}_{6}$ & 50 & 10 & 6 & 5 & 6 & 500 & 300 & 250 & 300 \\
\hline $\mathrm{P}_{7}$ & 45 & 10 & 6 & 5 & 6 & 450 & 270 & 225 & 270 \\
\hline $\mathrm{P}_{8}$ & 50 & 10 & 6 & 5 & 6 & 500 & 300 & 250 & 300 \\
\hline $\mathrm{P}_{9}$ & 50 & 10 & 6 & 5 & 6 & 500 & 300 & 250 & 300 \\
\hline $\mathrm{P}_{10}$ & 30 & 10 & 6 & 5 & 6 & 300 & 180 & 150 & 180 \\
\hline $\mathrm{P}_{11}$ & 30 & 12 & 5 & 5 & 18 & 360 & 150 & 150 & 540 \\
\hline
\end{tabular}

\subsection{Solving the Formulated Mathematical Model}

The most prominent algorithm to solve LP problems is the Simplex Algorithm developed by Dantzig in 1947. However, the formulated model has integer decision variables and therefore it is referred to as Integer Linear Programming (ILP). Thus, the problem cannot be solved using the simplex method alone. One class of exact algorithms that can be used to solve ILP is cutting plane methods [20]. This method first uses LP relaxation and afterward adds linear constraints so that it will lead the solution towards being integer without excluding any integer feasible points. Another class of exact algorithms is variants of the branch and bound method [21]. Many problems are intractable since ILP is NP-hard (see [22]), thus heuristic methods are used instead. Hill climbing (see [23]), simulated annealing (see [24]), and ant colony optimization (see [25]) are some of the heuristic methods that can be applied to solve ILPs. However, in this study spreadsheet paradigm was used to solve the formulated ILP problem.

\section{Model in Microsoft Excel}

The above integer linear programming model was implemented in Microsoft 
Excel (see Figure 2). Major spreadsheet packages come with a built-in optimization tool called Solver. MacDonald [26] explained how to use Microsoft Excel Solver to solve LP problems. Many authors in the literature have used the Excel Solver to solve different linear and integer linear programming problems [27] [28]. Once a model was implemented in a spreadsheet, the optimal values of the decision variables and the optimal objective function value can be found using Excel Solver. In the Solver dialog box, Simplex LP was selected to solve the ILP implemented in Excel as a spreadsheet model, where Solver uses a Branch and Bound to solve the model. The demand constraint should be satisfied by any solution of this problem as it was identified as a hard constraint. The number of working hours, working days were changed within a particular range acceptable to the management, and a feasible solution was found when the number of working hours was increased up to 8.5 hours, while number of labours assigned for each section considered constant. Since the production process is continuous, labourers and machines in all sections should work for additional 0.5 hours. As a result, the right-hand side of the machine hour and labour hour constraint were changed as displayed in the spreadsheet model in Figure 2. The overtime cost can be calculated separately, thus, it is not included in the spreadsheet model.

\section{Results and Discussion}

\subsection{Results}

According to the obtained optimum solution, the number of batches to be

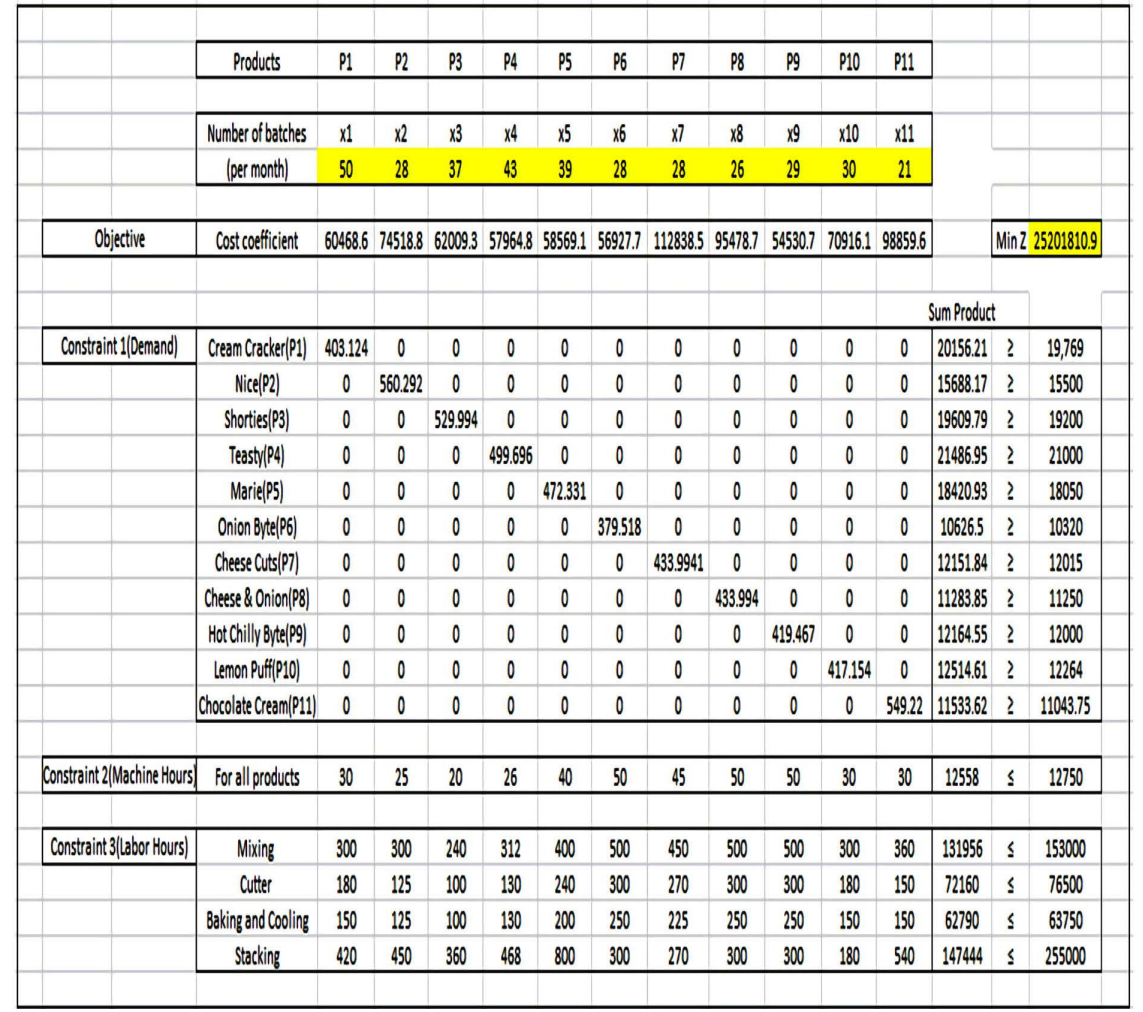

Figure 2. The spreadsheet model and solution as exhibited in Excel. 
produced from each product per month is displayed in Figure 2, and according to Figure 2, monthly demand can be satisfied using the available resources with a minimum cost of approximately Rs.25.2 million. In order to achieve that, the plant should produce following number of batches from each product:

$x_{1}($ Cream Cracker $)=50, x_{2}($ Nice $)=28, x_{3}($ Sorties $)=37, x_{4}($ Teasty $)=43, x_{5}$ (Marie) $=39, x_{6}($ Onion byte $)=28, x_{7}$ (Cheese cuts) $=28, x_{8}$ (Cheese and Onion) $=26, x_{9}($ Hot chilly Byte $)=29, x_{10}($ Lemon Puff $)=30, x_{11}($ Chocolate Cream $)=$ 21.

Moreover, in order to satisfy the customer demand, the manufacturing plant should function 25 days and 8.5 hours continuously each day for this particular month.

\subsection{Discussion}

The Excel does not provide sensitivity report, as the variables are integers. Therefore, sensitivity analysis cannot be performed for the optimal solution. The total monthly cost can be reduced by Rs. 474,705 if the integer constraint is removed and this additional monthly cost is due to the excess amount of biscuits that will be produced due to the integer constraint. Consequently, if the company can produce partial batches, then the monthly additional cost of producing additional biscuits could be reduced and the excess amount of biscuits produced could be avoided.

In addition, the solved model (using sum product column) identifies the number of working hours and working days of the production plant per month and the total kilograms of biscuits from each product should be produced by the end of month. However, the minimum number of hours that the plant should function to get a feasible solution is 8.372 hours. However, it was round up to 8.5 considering the convenience of paying overtime. If we assume that all the 43 labourers are working 8.5 hours for all the 25 days even though for some products some labourers are kept idle, the overtime cost will be $(8.5-8) \times 25 \times 43 \times$ OTR, where OTR is the overtime rate. Moreover, idle times of labourers and machines can be obtained by observing the spreadsheet model.

Even though this study was carried out based on the data of a particular month, this model can be generalized to determine the number of batches to be produced for any month. As $D_{i}^{\prime}$ s are changing from month to month, applying new $D_{i}$ 's to the formulated spreadsheet model would give the number of products to be produced in each month. In addition, number of working hours and working days can be appropriately changed in the model until it reaches feasibility.

For further analysis of the business, the management can analyze the future demand after identifying a probability distribution for the monthly demand and modelling a simulation to take an expected monthly demand. In addition, at the moment the management has not defined any goals but if they do, then a goal programming model can be used for this problem. 


\section{Conclusions}

Based on the results obtained above, the solved integer linear programming model gives a feasible solution and it minimizes the monthly manufacturing cost. It could be concluded that by implementing the production plan suggested by the solution, the monthly demand could be satisfied using the available resources while minimizing the monthly production cost.

Moreover, the management can schedule the production for each day, as the aggregate number of batches to be produced for each product and the numbers of labour hours needed for the month are predetermined. If the plant overproduced the biscuits, the biscuits would be remained in the finished goods stores for an additional period, which results in excessive amount of inventory cost. This will also lead to low quality products entering into the market, causing bad reputation to the production plant. Therefore, by implementing this production plan, manufacturing excess of biscuits can be avoided and hence utilizes the physical and human resources to the optimum manner. This will enable manufacturing plant to reduce the production cost. Moreover, using the proposed mathematical model and with the help of Excel spreadsheet, the company can plan the production for the coming years.

\section{Conflicts of Interest}

The authors declare no conflicts of interest regarding the publication of this paper.

\section{References}

[1] Kantorovich, L.V. (1939) The Mathematical Method of Production Planning and Organization. Management Science, 6, 363-422.

[2] Tingley, G.A. (1987) Can MS/OR Sell Itself Well Enough? Interfaces, 17, 41-52. https://doi.org/10.1287/inte.17.4.41

[3] Hanssmann, F. and Hess, S.W. (1960) A Linear Programming Approach to Production and Employment Scheduling. Management Science, 1, 46-51.

https://doi.org/10.1287/mantech.1.1.46

[4] Hung, Y.F. and Leachman, R.C. (1996) A Production Planning Methodology for Semiconductor Manufacturing Based on Iterative Simulation and Linear Programming Calculations. IEEE Transactions on Semiconductor Manufacturing, 9, 257-269. https://doi.org/10.1109/66.492820

[5] Pendharkar, P.C. (1997) A Fuzzy Linear Programming Model for Production Planning in Coal Mines. Computers \& Operations Research, 24, 1141-1149. https://doi.org/10.1016/S0305-0548(97)00024-5

[6] Vasant, P.M. (2003) Application of Fuzzy Linear Programming in Production Planning. Fuzzy Optimization and Decision Making, 2, 229-241. https://doi.org/10.1023/A:1025094504415

[7] Wang, R.C. and Liang, T.F. (2004) Application of Fuzzy Multi-Objective Linear Programming to Aggregate Production Planning. Computers \& Industrial Engineering, 46, 17-41. https://doi.org/10.1016/j.cie.2003.09.009

[8] Wang, R.C. and Liang, T.F. (2005) Applying Possibilistic Linear Programming to 
Aggregate Production Planning. International journal of production economics, 98, 328-341. https://doi.org/10.1016/j.ijpe.2004.09.011

[9] Kanyalkar, A.P. and Adil, G.K. (2005) An Integrated Aggregate and Detailed Planning in a Multi-Site Production Environment Using Linear Programming. International Journal of Production Research, 43, 4431-4454. https://doi.org/10.1080/00207540500142332

[10] da Silva, C.G., Figueira, J., Lisboa, J. and Barman, S. (2006) An Interactive Decision Support System for an Aggregate Production Planning Model Based on Multiple Criteria Mixed Integer Linear Programming. Omega, 34, 167-177. https://doi.org/10.1016/j.omega.2004.08.007

[11] Goodman, D.A. (1974) A Goal Programming Approach to Aggregate Planning of Production and Work Force. Management Science, 20, 1569-1575.

https://doi.org/10.1287/mnsc.20.12.1569

[12] Jamalnia, A. and Soukhakian, M.A. (2009) A Hybrid Fuzzy Goal Programming Approach with Different Goal Priorities to Aggregate Production Planning. Computers \& Industrial Engineering, 56, 1474-1486. https://doi.org/10.1016/j.cie.2008.09.010

[13] Leung, S.C. and Chan, S.S. (2009) A Goal Programming Model for Aggregate Production Planning with Resource Utilization Constraint. Computers \& Industrial Engineering, 56, 1053-1064. https://doi.org/10.1016/j.cie.2008.09.017

[14] Masud, A.S. and Hwang, C.L. (1980) An Aggregate Production Planning Model and Application of Three Multiple Objective Decision Methods. International Journal of Production Research, 18, 741-752. https://doi.org/10.1080/00207548008919703

[15] Wang, R.C. and Fang, H.H. (2001) Aggregate Production Planning with Multiple Objectives in a Fuzzy Environment. European Journal of Operational Research, 133, 521-536. https://doi.org/10.1016/S0377-2217(00)00196-X

[16] Wolsey, L.A. (1998) Integer Programming. Wiley, New York.

[17] Orcun, S., Altinel, I.K. and Hortaçsu, Ö. (2001) General Continuous Time Models for Production Planning and Scheduling of Batch Processing Plants: Mixed Integer Linear Program Formulations and Computational Issues. Computers \& Chemical Engineering, 25, 371-389. https://doi.org/10.1016/S0098-1354(00)00663-3

[18] Floudas, C.A. and Lin, X. (2005) Mixed Integer Linear Programming in Process Scheduling: Modeling, Algorithms, and Applications. Annals of Operations Research, 139,131-162. https://doi.org/10.1007/s10479-005-3446-x

[19] Hvolby, H.H. and Steger-Jensen, K. (2010) Technical and Industrial Issues of Advanced Planning and Scheduling (APS) Systems. Computers in Industry, 61, 845-851. https://doi.org/10.1016/j.compind.2010.07.009

[20] Gomory, R.E. (1963) An Algorithm for Integer Solutions to Linear Programs. Recent Advances in Mathematical Programming, 64, 260-302.

[21] Land, A. and Doig, A. (1960) An Automatic Method of Solving Discrete Programming Problems. Ecometrics, 28, 497-520. https://doi.org/10.2307/1910129

[22] Schrijver, A. (1998) Theory of Linear and Integer Programming. John Wiley \& Sons, New York.

[23] Beale, E.M.L. (1985) Integer Programming. Computational Mathematical Programming, 15, 1-24. https://doi.org/10.1007/978-3-642-82450-0_1

[24] Abramson, D. and Randall, M. (1999) A Simulated Annealing Code for General Integer Linear Programs. Annals of Operations Research, 86, 3-21. https://doi.org/10.1023/A:1018915104438

[25] Doerner, K.F., Gutjahr, W.J., Hartl, R.F., Strauss, C. and Stummer, C. (2006) Pareto 
Ant Colony Optimization with ILP Preprocessing in Multiobjective Project Portfolio Selection. European Journal of Operational Research, 171, 830-841.

https://doi.org/10.1016/j.ejor.2004.09.009

[26] MacDonald, Z. (1995) Teaching Linear Programming Using Microsoft Excel Solver. Computers in Higher Education Economics Review, 9, 7-10.

[27] Trick, M.A. (2004) Using Sports Scheduling to Teach Integer Programming. INFORMS Transactions on Education, 5, 10-17. https://doi.org/10.1287/ited.5.1.10

[28] Hojati, M. and Patil, A.S. (2011) An Integer Linear Programming-Based Heuristic for Scheduling Heterogeneous, Part-Time Service Employees. European Journal of Operational Research, 209, 37-50. https://doi.org/10.1016/j.ejor.2010.09.004 